\title{
Comparison of ice-shelf creep flow simulations with ice- front motion of Filchner-Ronne Ice Shelf, Antarctica, detected by SAR interferometry
}

\author{
Christina L. Hulbe, ${ }^{1}$ Eric Rignot, ${ }^{2}$ Douglas R. MacAyeal ${ }^{1}$ \\ ${ }^{1}$ Department of the Geophysical Sciences, University of Chicago, Chicago, IL 60637, U.S.A. \\ 2 Jet Propulsion Laboratory, California Institute of Technology, Pasadena, CA 91109, U.S.A.
}

\begin{abstract}
Comparison between numerical model ice-shelf flow simulations and synthetic aperture radar (SAR) interferograms is used to study ice-flow dynamics at the Hemmen Ice Rise (HIR) and Lassiter Coast (LC) corners of the iceberg-calving front of the Filchner-Ronne Ice Shelf, Antarctica. The interferograms are constructed from SAR images provided by the European Space Agency's remote-sensing satellites (ERS-1/2). Narrow bands of large shear strain rate are observed along the boundaries between fastflowing ice-shelf ice and no-flow boundaries. Large rifts, opened where the ice shelf separates from the coast, appear to be filled with a melange of sea ice, ice-shelf fragments, and snow. Trial and error is used to find the best match between artificial interferograms, constructed from modelled ice flow, and the observed interferograms. We find that at both HIR and LC, ice within the coastal boundary layers must be significantly softer than adjacent ice. At HIR the rift-filling ice melange transmits stress from one ice-shelf fragment to another; thus it must have mechanical competence and must moderate both separation of the ice shelf from the coast and the release of icebergs. However, the ice melange along the LC does not. The difference may be related to melange thickness, which could vary in the two locations due to differences in sub-ice-shelf oceanography or perhaps to regional atmospheric warming, currently under way along the Antarctic Peninsula. Future warming could weaken the melange ice around HIR as well, causing the ice shelf to lose contact with that shelf-front anchor.
\end{abstract}

\section{INTRODUCTION}

Understanding the dynamical processes that govern the location of iceberg-calving fronts of ice shelves in the Ross and Weddell Seas is a long-standing problem in Antarctic ice-sheet stability and response to climate change. These processes influence directly the areal extent of the ice sheet and the net heat and salt exchanges between air and sea. It is clear that the mechanical connection between an ice shelf and the bay walls that confine it and the ice rises and islands that penetrate into it is important in maintaining a stable shelf-front position. The nature of that connection is not well understood, because extensive crevassing and iceberg calving make field observations of ice-shelf margins both difficult and dangerous.

Historical data indicate that calving from large ice shelves is episodic, with long periods of ice-front advance punctuated by short periods of relatively rapid retreat (see, e.g., Jacobs and others, 1986; Rott and others, 1996). This cyclic behavior suggests that the mean front position depends on glaciological factors such as the rate of ice-spreading required to maintain contact with confining bay walls (Sanderson, 1979) and the formation of large-scale rifts that provide the planes of weakness along which tabular icebergs calve. However, correlations between retreat of small ice shelves and southward migration of the $-5^{\circ} \mathrm{C}$ mean annual atmospheric surface isotherm around the Antarctic Peninsula (Vaughan and Doake, 1996) suggest that environmental factors may determine the mean ice-front position. A successful description of ice-shelf front stability must accommodate those two seemingly independent controls on ice-front location, one an "internal" glaciological control and the

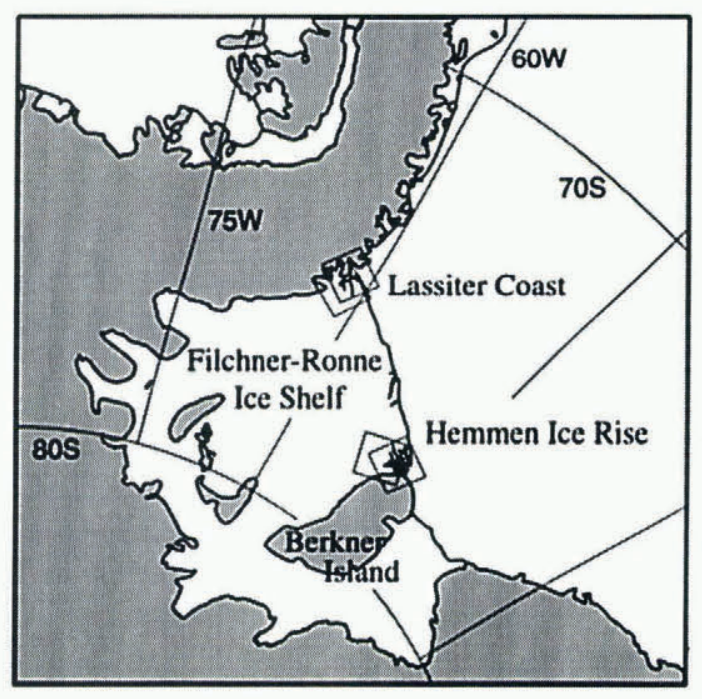

Fig. 1. Sketch map of the Filchner-Ronne Ice Shelf. Grounded ice and ice-free rock are shaded grey. Rectangles around the Lassiter Coast and Hemmen Ice Rise areas indicate the locations of SAR images and interferograms used in this study ( shown in Figs 2 and 3). 


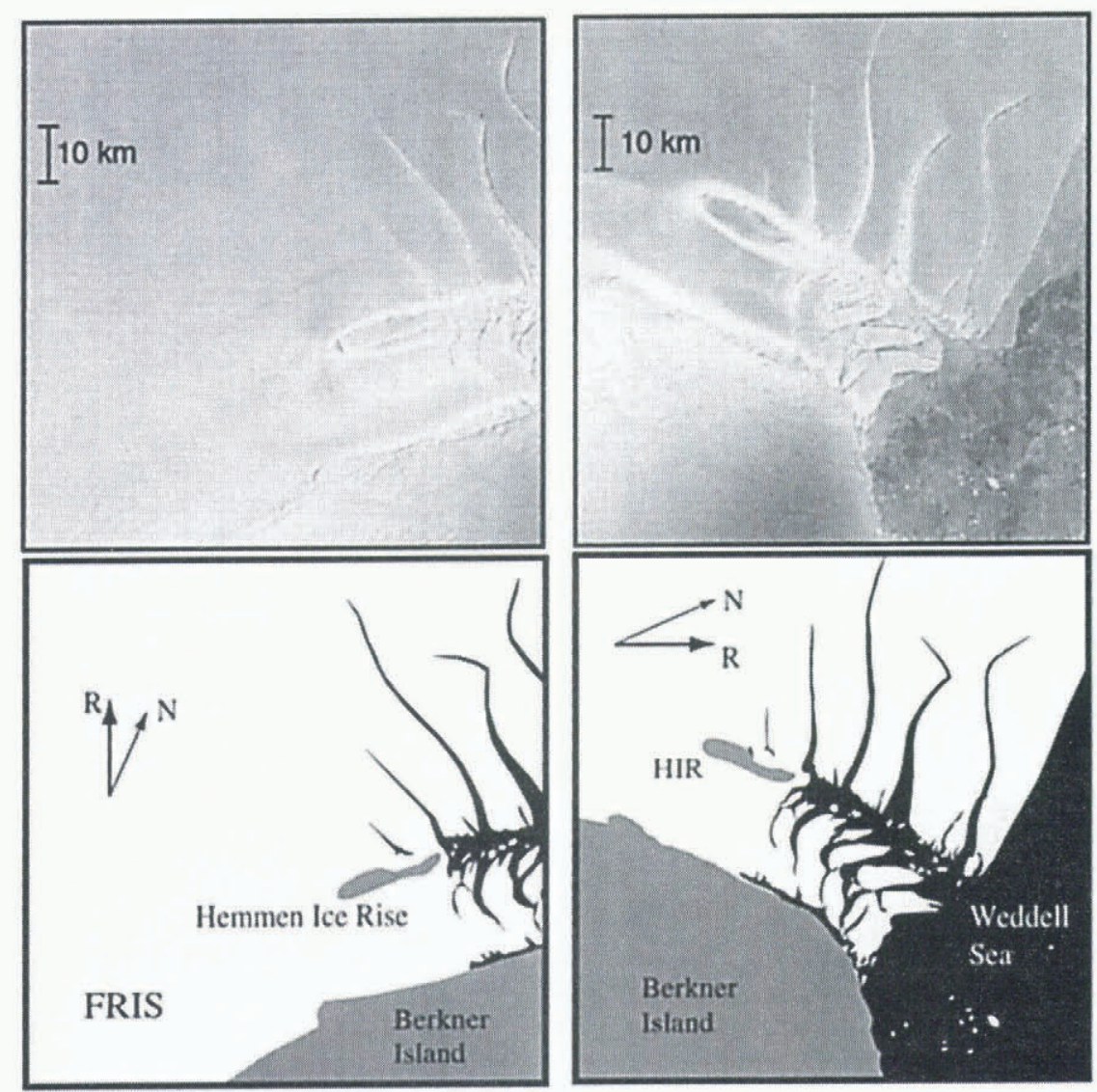

Fig. 2. SAR amplitude images and sketch maps (from Rignot and MacAyeal, in press), indicating prominent features in the HIR area. Descending satellite pass images are in the lefthand column, and ascending pass images in the righthand column. North is indicated by the arrow labelled $\mathcal{N}$, and the satellite look direction is indicated by the arrow labelled $R$. Several features stand out in the HIR and LC (Fig. 3) images: radar-bright bands that indicate extreme crevassing due to shear along coastal boundaries; rifts generated where the sheared ice is advected downstream, in the wake of HIR and along the LC, in the wake of the unnamed promontory east of Hansen Inlet; and the melange of multi-year sea ice, ice-shelf fragments and snow that fills rifts and coastal separation cavities in both locations.

other an "external" climate control. Here, a link between internal and external controls is identified, using interferometric observations and finite-element modelling of the separation of the Filchner-Ronne Ice Shelf (FRIS) from Hemmen Ice Rise (HIR) and from the Lassiter Coast (LC).

The HIR and LC corners of the FRIS calving front (Fig. 1) illustrate two typical shelf-front geometries: at HIR the ice-shelf front appears to be anchored by an intruding ice rise (and by Berkner Island), and along the LC the shelf front diverges from the wall of a widening bay. Synthetic aperture radar (SAR) images (Figs 2 and 3; from Rignot and MacAyeal, in press) reveal that at both locations the rifts and coastal separation cavities are filled with what appears to be a melange of multi-year sea ice, ice-shelf fragments and snow. Interferograms constructed by Rignot and MacAyeal (in press) from these SAR images show that the melange deforms, presumably in response to ice-shelf flow. Finite-element models that are tuned to match the interferograms suggest that at HIR the melange must possess sufficient mechanical strength to influence ice-shelf flow and maintain some mechanical interaction between the ice shelf and coast after the ice shelf has separated from the coast. In contrast, the melange along the LC does not appear to influence ice-shelf flow.

The link between glaciological and climate controls on the position of an ice-shelf front, suggested by the present work, is as follows. Large-scale rifting and coastal separa- tion occur at a number of locations within an ice shelf (e.g. around ice rises and along coastal promontories). The seaward front of the ice shelf forms where weaknesses introduced by those processes result in iceberg calving. Rifting and separation in cold environmental conditions fail to produce an ice-shelf front, because the ice melange that fills the voids reconnects the ice shelf mechanically across rifts and with the coast. Where local environmental conditions do not permit the melange to bind the ice shelf together, rifting and separation produce an ice-shelf front. Moreover, we suggest that because the thin melange will melt more rapidly than the thicker ice-shelf ice, it may facilitate rapid shelffront retreat in future-warming scenarios.

\section{DATA AND MODEL DESGRIPTION}

Ice-shelf flow and tidal motion in the LC area are observed using SAR interferograms derived from eight passes of the European remote-sensing satellites (ERS-1/2) during their tandem mission in early 1996. A sequence of seven SAR images from the 1992 ERS-1 "ice phase" mission is used to observe the area around HIR. Both sets of observations are described in Rignot and MacAyeal (in press). One ascending- and one descending-satellite-pass interferogram, filtered for tidal motion (using the interferogram differencing methods described by Rignot and MacAyeal), are used for each location. 

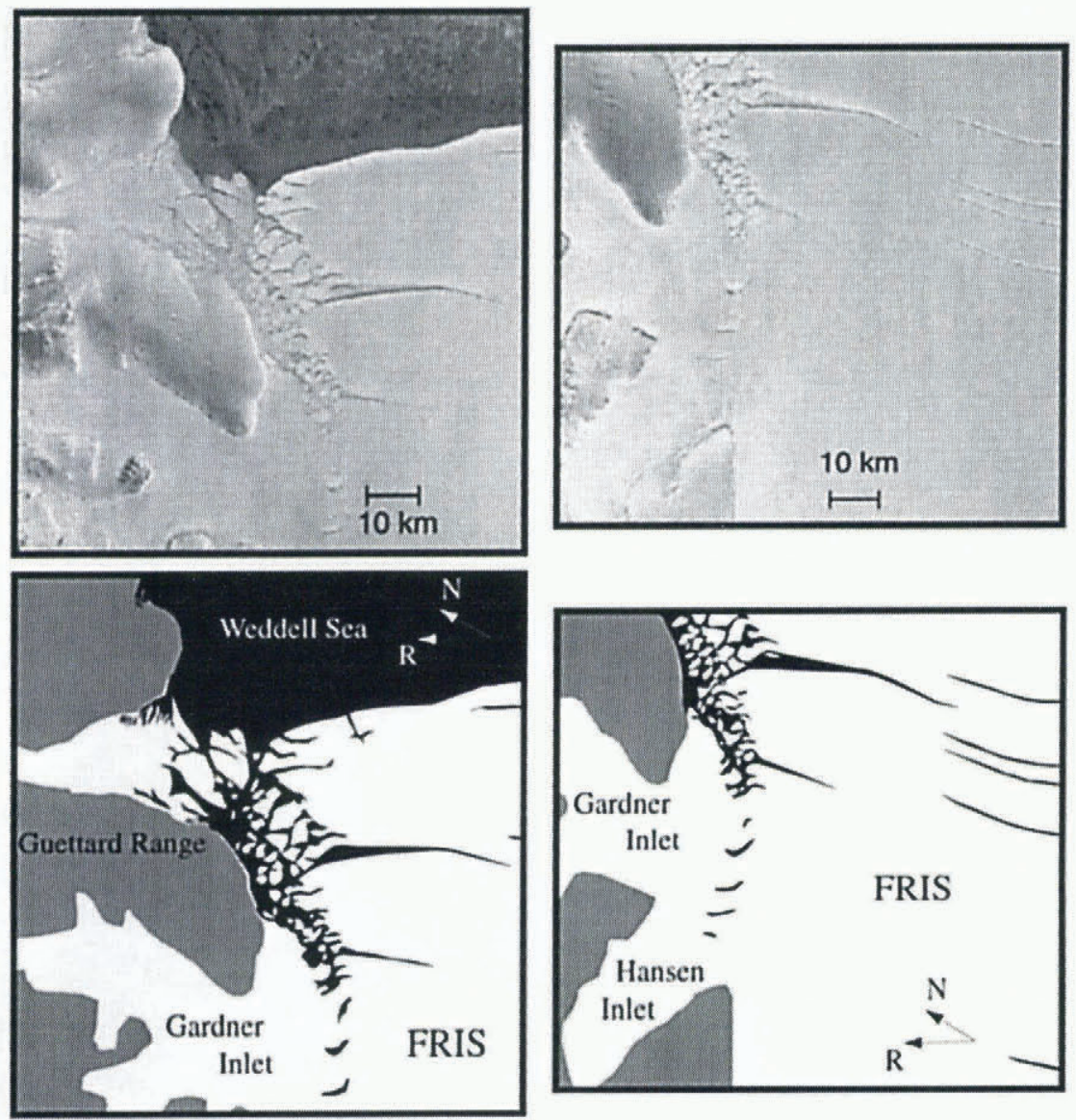

Fig. 3. SAR amplitude images and sketch maps (from Rignot and MacAyeal, in press), indicating prominent features in the LC area. Image arrangement is as in Figure 2.

Interpreting the pattern of ice motion depicted in the interferograms is slightly complicated because the motion is in the line-of-sight of the orbiting satellite, rather than in the plane of the ice shelf or along an ice flowline. Also, the dynamical implications of ice displacement may not be obvious. We address these limitations by visual comparison between the observations and artificial interferograms that correspond to the satellite look direction of the observations. The artificial interferograms are created using a finite-element numerical model of ice-shelf flow in the same area as that covered by the interferograms. The model (described in MacAyeal and others, in press; see also MacAyeal and others, 1996) computes ice velocity for given ice thicknesses and boundary conditions, using the typical ice-shelf stressbalance equations and assumptions about ice rheology. The finite-element mesh resolution is fine enough to trace rift boundaries and accommodate narrow boundary layers.

\section{MODEL-SENSITIVITY EXPERIMENTS}

Two series of sensitivity experiments, in which ice softness and melange ice thickness are varied, are used to investigate the importance of coastal boundary-layer softening and of the ice melange that fills shelf-front rifts at HIR and along the LC. The cause of ice softening is not specified, but it is reasonable to assume that some softening due to strain heating and ice-crystal alignment will occur within the rapidly shearing margin between fast-flowing ice-shelf ice and the adjacent coast (see, e.g., Echelmeyer and others, 1994; Fujita and Mae, 1994). The melange is idealized simply as thin ice, with the same rheologic properties and dynamical behavior as the surrounding ice shelf. Melange thickness will vary, due to ice-flow divergence, the age of the melange material, and environmental conditions, but because we do not intend to reproduce the interferograms exactly (as might be possible with a formal inverse method), that simplification is acceptable. Our goal is to determine the combination of model parameters which best accounts for the observed dynamical processes.

A qualitative assessment of model performance for the assumptions in each experiment is made by comparing artificial and observed interferograms. We compare fringe spacing and orientation but not absolute velocities, because the processing required to derive velocity from the interferograms cannot be performed everywhere in the images and because velocity errors are large (at best, about $15 \%$; discussed by Rignot and MacAyeal, in press). Error in the comparisons made here should be limited to error in the observed interferometric fringes, typically about $1 / 28$ of a fringe, and to error due to unfiltered tidal displacement.

Four experiments are conducted with the LC model. Experiment 1 assumes no boundary-layer ice softening and has open-water rifts. Experiment 2 assumes a boundary-layer ice softening of $50 \%$ (a flow-law-rate constant of $1 \times 10^{8}$ $\mathrm{Pa} \mathrm{s}^{-1 / 3}$, reduced from $2 \times 10^{8} \mathrm{~Pa} \mathrm{~s}^{-1 / 3}$ ) in a $5 \mathrm{~km}$ wide band along the unnamed promontory east of Hansen Inlet, extending downstream in the crevassed wake of the promontory, and has open-water rifts. Experiment 3 assumes no boundary-layer ice softening and fills the rifts with a $25 \mathrm{~m}$ thick ice melange. Experiment 4 assumes a boundary-layer ice softening of $50 \%$ and has a melange thickness of $25 \mathrm{~m}$. 

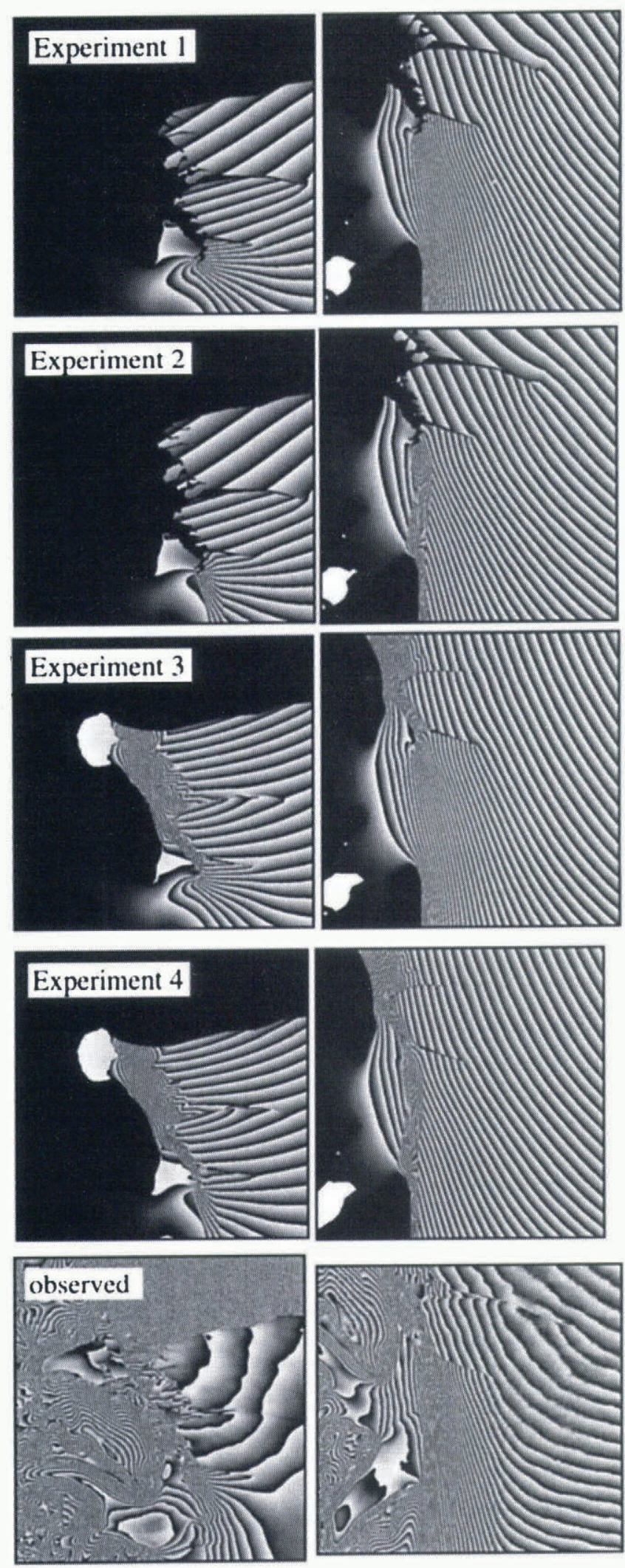

Fig. 4. Artificial and observed interferograms for the $L C$ experiments. Descending satellite pass images are in the lefthand column, and ascending pass images in the righthand column. The best match between artificial and observed interferograms is for experiment 2, where a $50 \%$ coastal boundary-layer softening is applied and open-water rifts are assumed. The observed interferograms are from Rignot and MacAyeal (in press).

The individual HIR experiments are similar to the LC experiments and so are not described here; their details can be found in MacAyeal and others (in press).
Results of the LC experiments are depicted in Figure 4. The best match between artificial and observed interferograms is achieved in experiment 2. Boundary-layer softening is required to reproduce the narrow fringe spacing along and downstream of the promontory east of Hansen Inlet. Fringe spacing and orientation near the front of the ice shelf are best reproduced when the rifts are simulated as being ice-free. Thus, the rift-filling ice melange observed in the LC images and interferograms does not influence flow in the main ice shelf and must not be a mechanically competent unit.

The most favorable comparisons for the HIR experiments (Fig. 5; from MacAyeal and others, in press, figs 6 and 7) are obtained with $50 \%$ coastal boundary-layer softening and a melange thickness of $10 \mathrm{~m}$. Boundary-layer ice softening is required to reproduce the narrow fringe spacing around HIR and along the coast of Berkner Island, and the thin, contiguous layer of rift-filling ice must be present to reproduce the observed fringe spacing and orientation within the main ice shelf. The melange ice must therefore be mechanically competent enough to transmit stress across rifts and between ice-shelf fragments. Its effect is to bind together the rifted shelf front.

\section{DISCUSSION}

The comparison between model-derived and observed interferograms presented here demonstrates the dynamical importance of two features of ice-shelf front corners. First, coastal boundary-layer ice must be substantially softer than adjacent ice-shelf ice. At both HIR and the LC, the soft ice is advected downstream into areas where rifting begins (in the wake of HIR in Figure 2 and downstream of the promontory east of Hansen Inlet in Figure 3). Weakness introduced into the ice shelf by this softening may determine where rifting begins and shelf fronts form. That weakness may be opposed by the second feature studied here, the ice melange that fills shelf-front rifts and coastal separation cavities. At HIR, the melange provides mechanical coupling across rift walls and between the ice shelf and the adjacent coasts of HIR and Berkner Island. That coupling binds together the rift walls, along which large icebergs eventually calve, and it maintains a connection to Berkner Island farther seaward than horizontal spreading of ice-shelf ice would allow. The ice melange probably allows the shelf front to extend beyond the stable position that would be determined by internal controls alone, by preventing or delaying iceberg calving.

The ice melange may also be the ice-shelf front's Achilles' heel, because it would be more vulnerable to melting than thicker ice-shelf ice. Indeed, melange ice, though present along the LC, offers no mechanical coupling between the shelf front and the adjacent coast. The reason for that difference in melange competence at HIR and the LC may reflect a difference in melange thickness or temperature. The LC ice melange could be warmed and melted as high-salinity shelf water flows below the ice shelf, along the western boundary of the Weddell Sea (Jacobs and others, 1985). Another tantalizing possibility is that the melange provides the link between shelf-front position, ice dynamics and climate. The southward progression of atmospheric warming observed around the Antarctic Peninsula (Vaughan and Doake, 1996) may be weakening the thin layer of ice. The LC is $3^{\circ}$ north of HIR, and so the ice mel- 

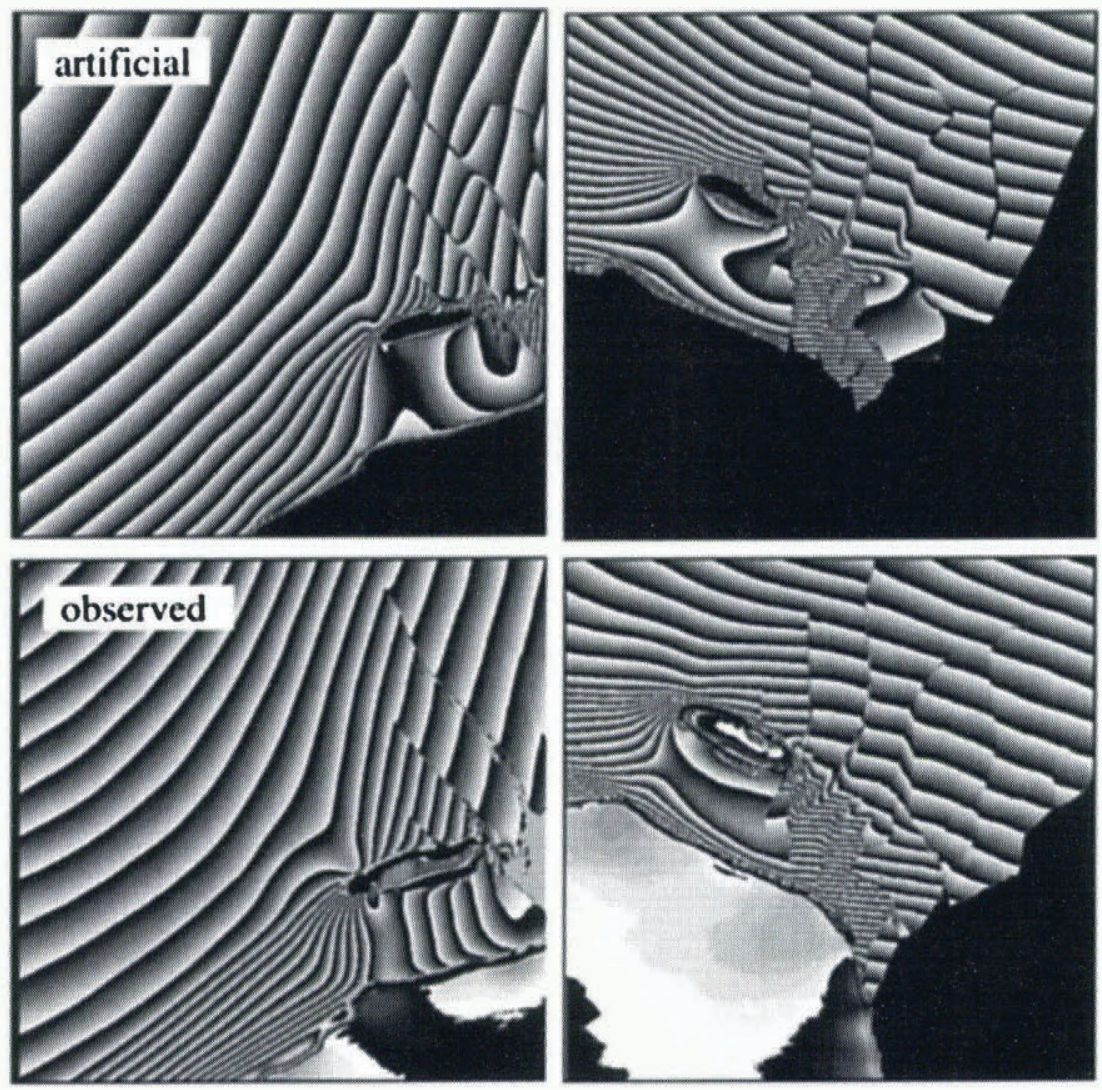

Fig. 5. The most favorable HIR experiment results and observed interferograms (from Mac Ayeal and others, in press, figs 6 and 7). In this experiment, a $50 \%$ coastal boundary-layer softening is applied and rifts are assumed to contain a $10 \mathrm{~m}$ thickness of melange ice. Image arrangement is as in Figure 4.

ange there may be responding to regional warming sooner than at HIR.

An example of the vulnerability of rift-filling ice to regional warming may be the sudden disaggregation of the Larsen-A Ice Shelf in January 1995 (Rott and others, 1996). The break-up, during a storm, followed several consecutive warm summer seasons. It is possible that water-filled crevasses penetrated the entire thickness of the shelf, creating a network of wounds held together by remaining bridges between crevasses and by frozen seawater within the crevasses, similar to the melange observed here within the LC and HIR rifts. The crevasse-filling melange, weakened by a particularly warm summer (suggested by extensive melt ponds on the surface of the ice shelf), would have been more vulnerable to failure during a large storm event than the thicker ice shelf. The atmospheric and sea-surface warming currently under way around the Antarctic Peninsula may progress southward, toward the Antarctic interior. That warming could weaken rift-filling sea-ice melange, making events like those on Larsen-A more common around Antarctica.

\section{ACKNOWLEDGEMENTS}

Support for this research was provided by the European Space Agency (ERS-1/2 project code: AO2.USA.160), the U.S. National Aeronautics and Space Administration (NAGW-5005) and a NASA Graduate Student Fellowship (awarded to C. L. Hulbe). We thank A. Gabriel for help in the project inception. D. Vaughan, C. Doake, R. Frolich and other colleagues at the British Antarctic Survey pro- vided ice-thickness data for the FRIS and many suggestions during the course of the research reported here. The manuscript was improved by comments from J. A. van Zanten, G. H. Gudmundsson and an anonymous reviewer.

\section{REFERENCES}

Echelmeyer, K. A., W. D. Harrison, C. Larsen and J. E. Mitchell. 1994. The role of the margins in the dynamics of an active ice stream. 7. Glaciol., 40(136), 527-538.

Fujita, S. and S. Mae. 1994. Strain in the ice sheet deduced from the crystalorientation fabrics from bare icefields adjacent to the Sør-Rondane Mountains, Dronning Maud Land, East Antarctica. J. Glaciol., 40(134), 135-139.

Jacobs, S. S., R. G. Fairbanks and Y. Horibe. 1985. Origin and evolution of water masses near the Antarctic continental margin: evidence from $\mathrm{H}_{2}{ }^{18} \mathrm{O} / \mathrm{H}_{2}{ }^{16} \mathrm{O}$ ratios in seawater. In Jacobs, S. S., ed. Oceanology of the Antarctic continental shelf. Washington, DC, American Geophysical Union, 59-85. (Antarctic Research Series 43.)

Jacobs, S. S., D. R. MacAyeal and J. L. Ardai, Jr. 1986. The recent advance of the Ross Ice Shelf, Antarctica. J. Glaciol., 32(112), 464-474.

MacAyeal, D. R., V. Rommelaere, P. Huybrechts, C. L. Hulbe, J. Determann and C. Ritz. 1996. An ice-shelf model test based on the Ross Ice Shelf. Ann. Glaciol., 23, 46-51.

MacAyeal, D. R., E. Rignot and C. L. Hulbe. In press. Ice-shelf dynamics near the front of the Filchner-Ronne Ice Shelf, Antarctica, revealed by SAR interferometry: model/interferogram comparison. 7. Glaciol.

Rignot, E. and D. R. MacAyeal.In press. Ice-shelf dynamics near the front of the Filchner-Ronne Ice Shelf, Antarctica, revealed by SAR interferometry. J. Glaciol.

Rott, H., P. Skvarca and T. Nagler. 1996. Rapid collapse of northern Larsen Ice Shelf, Antarctica. Science, 271(5250), 788-792.

Sanderson, T. J. O. 1979. Equilibrium profile of ice shelves. f. Glaciol., 22(88), 435-460.

Vaughan, D. G. and C. S. M. Doake. 1996. Recent atmospheric warming and retreat of ice shelves on the Antarctic Peninsula. Nature, 379(6563), 328-331. 